\title{
Management of Life Threatening Post-Partum Hemorrhage with HBOC-201 in a Jehovah's Witness
}

\author{
Andrea Mytinger, DO' \\ Elyce Sheehan, MD' \\ Nathan Blue, MD \\ Kendall P. Crookston, $M D, P h D^{3}$ \\ Ali I. Saeed, $M D^{4}$
}

1Department of Internal Medicine, ${ }^{2}$ Department of Maternal and Fetal Medicine,

${ }^{3}$ Departments of Pathology of Transfusion Medicine, and ${ }^{4}$ Divisions of

Pulmonary, Sleep and Critical Care Medicine

University of New Mexico School of Medicine

Albuquerque, NM USA

\begin{abstract}
Background: Post-partum hemorrhage remains the leading cause of maternal mortality worldwide. The obstetrician and critical care physician should be aware of local alternative treatment options for symptomatic anemia secondary to postpartum hemorrhage in patients who cannot receive red blood cell transfusion. Transfusion may not be an option due to strong personal belief, lack of compatible blood, or blood shortage.

Case: A 21 -year-old woman, gravida 1 para 1001, was transferred to a tertiary care center for management of severe post-partum hemorrhage (hemoglobin 4.2 $\mathrm{g} / \mathrm{dL}$ ). She had undergone emergent dilation and curettage followed by Bakri tamponade balloon placement at an outside facility. As a member of the Jehovah's Witness faith, she refused red blood cell transfusion. HBOC-201, a bovine hemoglobin based oxygen carrier, was successfully used to reverse symptomatic, life-threatening anemia.

Conclusion: HBOC-201 can act as a means to reverse severe end-organ damage for patients with severe post-partum hemorrhage and should be considered when no other treatment options are available.
\end{abstract}

\section{Teaching Points}

1. HBOC-210 (Hemopure $\left.{ }^{\circledR}\right)$ is a bovine hemoglobin-based oxygen carrier (HBOC), used as a means to reverse severe anemia in those patients who cannot receive $\mathrm{RBC}$ transfusion.

2. The current generation of HBOCs carry fewer side effects than their predecessors. Common side effects include transient hypertension, abdominal complaints, jaundice, elevated liver and pancreatic enzymes and decreased urine output.

3. The teratogenic effects of HBOC-201 remains unknown in humans. 


\section{Introduction}

Worldwide, there are an estimated 14 million pregnancy-related hemorrhages each year and $25 \%$ of maternal mortality can be attributed to post-partum hemorrhage (1). While the majority of post-partum hemorrhage leading to acute blood loss anemia is treated with red blood cell (RBC) transfusion, there remains a significant subset of patients who are unable to receive this life-saving modality. In instances where RBC transfusion is not an option due to lack of compatible blood, blood shortage, or strong patient personal beliefs, there remain alternative options for management. We report the case of a young Jehovah's Witness who presented with symptomatic anemia secondary to severe postpartum hemorrhage, treated successfully with an experimental protocol using HBOC-201 (Hemopure®).

\section{Case}

A 21-year-old female, gravida 1 para 1001, Jehovah's Witness was transferred to a tertiary care hospital for management of post-partum hemorrhage after spontaneous vaginal delivery at 40 weeks of gestation. The patient received 3 boluses of intravenous oxytocin, $800 \mathrm{mcg}$ of misoprostol and 1 dose of intramuscular (IM) carboprost trimethamine. She then underwent a dilation and curettage for presumed retained products of conception. A Bakri tamponade balloon catheter (figure 1) was placed vaginally and the patient was transferred for a higher level of care.

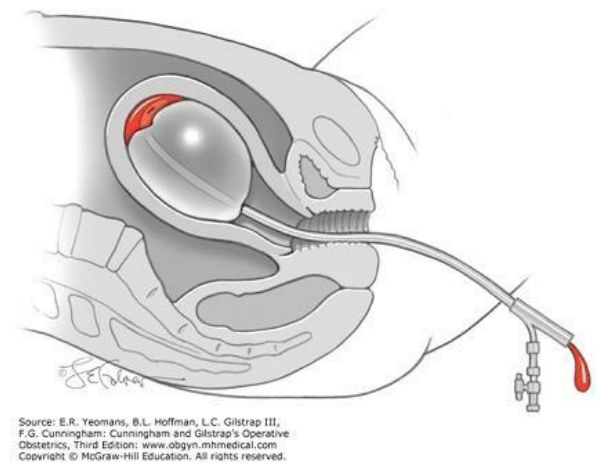

Figure 1. An example illustration of the Bakri vaginal tamponade balloon, placed in the uterus in attempt to apply pressure to bleeding vessels.

Prior to delivery, the patient's hemoglobin $(\mathrm{Hb})$ and hematocrit $(\mathrm{Hct})$ were initially $12.4 \mathrm{~g} / \mathrm{dL}$ and $36.4 \%$, respectively, which decreased to $5.5 \mathrm{~g} / \mathrm{dL}$ and $16.4 \%$. On arrival, the patient 's heart rate was 148 beats per minute while on $2 \mathrm{~L}$ of oxygen. The blood pressure was $93 / 36 \mathrm{mmHg}$. She was pale and tired-appearing with conjunctival pallor. Her abdomen exhibited generalized mild tenderness to palpation. The Bakri balloon was in place with $100 \mathrm{~mL}$ of drainage noted. Laboratory results revealed $\mathrm{Hb}$ of $4.2 \mathrm{~g} / \mathrm{dL}$, lactate of $1.2 \mathrm{mmol} / \mathrm{L}$ and troponin I of $1.820 \mathrm{ng} / \mathrm{mL}$. The patient refused transfusion of RBC, and the other major 
blood products, citing her faith. After a prolonged discussion, the patient consented to the use of HBOC-201.

The patient received 2 units of HBOC-201 along with 1,000 mg of ascorbic acid. $\mathrm{Her} \mathrm{Hb}$ increased from $4.2 \mathrm{~g} / \mathrm{dL}$ to $4.8 \mathrm{~g} / \mathrm{dL}$, much less than the anticipated 1 $\mathrm{g} / \mathrm{dL}$ increase with each unit of HBOC-201 raising concern for ongoing hemorrhage. An ultrasound was performed which revealed ongoing bleeding from the lower uterine segment behind the balloon. Methylergonovine $0.2 \mathrm{mg} \mathrm{IM}$ every 6 hours was started and the patient received two additional units of HBOC201 however, during infusion of the second unit her oxygen requirement increased from $2 \mathrm{~L}$ by nasal cannula to $15 \mathrm{~L}$ high flow mask at $80 \%$ FiO2. The transfusion was stopped and a chest radiograph revealed diffuse parenchymal opacities with prominent interstitial markings and small bilateral pleural effusions suggestive if fluid overload / pulmonary edema. The patient then underwent gel foam uterine artery embolization by Interventional Radiology for definitive management.

On hospital day 2 the patient's heart rate was 114 beats per minute and $\mathrm{Hb}$ was $5.2 \mathrm{~g} / \mathrm{dL}$, prompting infusion of an additional 2 units of HBOC-201. Due to continued hypoxia and radiographic evidence of fluid overload, diuretic therapy was administered. Her oxygen requirement decreased to $5 \mathrm{~L}$ by nasal cannula, however did not improve from there despite a negative fluid balance, so a CT scan of the chest was performed which revealed significant bilateral basal atelectasis. The patient's oxygen requirement resolved with incentive spirometry. The Bakri vaginal balloon was removed and minimal bleeding was observed. On hospital day 3 the patient's blood pressure increased to $176 / 78 \mathrm{mmHg}$. This, in the setting of proteinuria, peripheral edema and elevated aspartate aminotransferase (AST) to 104 unit/L (6-58 Unit/L) raised a suspicion for postpartum preeclampsia with severe features. Intravenous magnesium sulfate was briefly initiated for seizure prophylaxis, however it was discontinued after her blood pressure stabilized and the hypertension was attributed to a possible side effect of HBOC-201.

The patient received a total of 7.5 units of HBOC-201 over the course of 4 days in the MICU. Her troponin peaked on hospital day 2 at $2.930 \mathrm{ng} / \mathrm{mL}$, and continued to downtrend with multiple infusions of HBOC-201. The patient's own hematocrit began rising on hospital day 5 (Figure 2). 


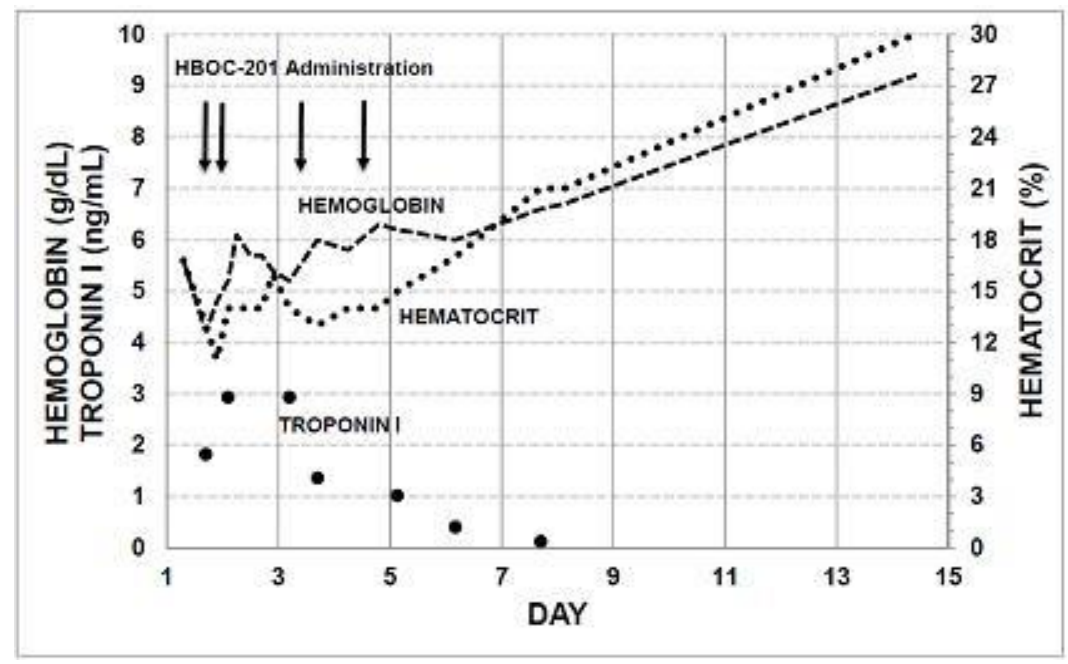

Figure 2. Illustration of the hemoglobin and hematocrit over the course of the patient's hospitalization and at her first out-patient follow up visit. The arrows indicate when HBOC-201 was infused. Troponin I is also depicted on this graph to illustrate the resolution of severe end-organ damage due to the severe anemia.

The patient was transferred to the obstetrics floor on hospital day 7 . In accordance with recent post-partum hemorrhage recommendations, she received $1025 \mathrm{mg}$ of IV iron dextran. She was discharged home in stable condition on hospital day 8 with a $\mathrm{Hb}$ of $6.7 \mathrm{~g} / \mathrm{dL}$ and Hct of $21 \%$. Outpatient follow-up revealed significant improvement in anemia with a $\mathrm{Hb}$ of $9.2 \mathrm{~g} / \mathrm{dL}$ and Hct of $30 \%$ one week after discharge.

\section{Discussion}

Acute post-partum hemorrhage leading to severe anemia remains the leading cause of maternal death worldwide (2). While the majority of post-partum hemorrhage leading to acute blood loss anemia is treated with transfusion of packed RBC or other blood products, there are certain subsets of patients who are unable to accept these products. This case demonstrates the use of a bovine hemoglobin-based oxygen carrier in a Jehovah's Witness patient with severe post-partum hemorrhage who refused blood products. There have been multiple case reports regarding the use of HBOC-201 in severely anemic Jehovah's Witness patients; however, there is no published report to our knowledge on the use of HBOC-201 in patients with symptomatic post-partum hemorrhage. Hemoglobin-based oxygen carriers were developed in response to the infectious issues associated with donor RBC and in an attempt to come up with an alternative treatment in those situations where RBC transfusion was not an option. The first generation of these products was known to cause renal toxicity and coagulopathy $(3,4)$. HBOC-201 is a second generation HBOC that is a cellfree, stroma-free, polymerized version of bovine hemoglobin. Because it contains no cell membrane, it is compatible with all blood types (no cross matching is 
needed). The shelf life is 36 months at room temperature (5) (no refrigeration or sophisticated supply network is needed). A number of randomized control trials have been done to evaluate HBOC-201 (and other similar products) as a potential RBC replacement. However, after infusion the short 24-hour half-life and statistical increase in adverse events associated with administration made it apparent that these HBOCs were not interchangeable with RBC for routine transfusion. While they are not interchangeable, many clinicians feel that the riskbenefit profile is favorable in severely anemic patients who cannot receive RBC. HBOC-201 is not yet approved for use in the United States, and therefore cannot be used outside of clinical trials. Several compassionate use studies are available in the United States to treat patients with life-threatening anemia when no other treatment option is available. Worldwide only a few countries have approved the use of HBOC-201 (6).

The side effect profile of the second generation HBOC's is much preferable to that of the first (4). Reported class effects of HBOC use include hypertension, esophageal dysmotility and increased risk for myocardial infarction, all of which are related to vasoconstriction secondary to increased nitric oxide scavenging in these products (5). HBOC-201 in particular, has not been reported to increase risk of myocardial infarction. Rather, it has been reported that HBOC-201 reduces cardiac hypoxia in the setting of severe anemia (7). Mongan et al. (8) found that, while HBOC-201 causes transient systemic and pulmonary hypertension in swine, blood flow to 8 major organs, including the heart, was unchanged compared to controls. Serruys et al. (9) found no significant change in coronary blood flow and no vasoconstriction in humans pre-oxygenated with HBOC-201 prior to Percutaneous Coronary Intervention for coronary artery disease. In this case, the patient presented with troponinemia, indicating type 2 demand ischemia in the setting of severe anemia. Troponin levels began to down-trend after HBOC-201 infusion.

Common side effects of HBOC-201 in particular include transient hypertension, abdominal complaints, jaundice, elevated liver and pancreatic enzymes (10) and bovine methemoglobinemia (11). To prevent the increased oxidation of infused HBOC-201 to methemoglobin, ascorbic acid is co-administered; methemoglobin levels should be monitored and treated with methylene blue should they become significantly elevated (5).

This patient did experience increased hypoxia while receiving a unit of HBOC201 which resulted in concern for transfusion reaction and transient discontinuation of the HBOC-201 infusion. It must be noted that HBOC-201 contains no cellular or plasma components, thus many transfusion reactions such as Transfusion Related Acute Lung Injury (TRALI) are an impossibility. HBOC-201 has been associated with volume overload; as it is a colloid this is a known complication (12). Volume overload was suspected, however, the patient did not improve with diuresis, and a chest CT revealed profound atelectasis. Given that her hypoxia greatly improved with incentive spirometry and 
ambulation, this was deemed unlikely to be a reaction associated with HBOC201 , but rather related to being bed-bound and critically ill.

One unit of HBOC-201 will raise serum $\mathrm{Hb}$ from $0.5 \mathrm{~g} / \mathrm{dL}$ to $2 \mathrm{~g} / \mathrm{dL}$ (12). One to two units of HBOC-201 are typically given for $\mathrm{Hb}$ levels $<6 \mathrm{~g} / \mathrm{DI}$, with additional units provided to maintain a goal Hemoglobin greater than $6 \mathrm{~g} / \mathrm{dL}(11,12)$. With a half-life of 19-24 hours $(5,13)$, HBOC-201 must be infused regularly until the patient's bone marrow production of RBC is sufficient, as evidenced by increases in hematocrit. It should be noted that HBOC-201 will only increase serum hemoglobin and not hematocrit; an initial decrease in hematocrit may be seen after infusion secondary to hemodilution (12).

The patient presented above experienced both transient hypertension and an increase in her serum AST, raising concern for post-partum preeclampsia. She was started on treatment for severe preeclampsia, however these affects were later attributed to the HBOC-201.

HBOC-201 is currently not recommended during pregnancy. One animal study in rats indicated that HBOC-201 infusion during organogenesis resulted in decreased litter size and increased incidence of external fetal malformations. This was thought to be related to decreased function of an inverted yolk sac, the primary nutritive organ for rat pups in utero (14). Holson et al. (15) performed a similar study on dogs which did not reveal a statistically significant difference in fetal malformations or other study end-points when compared to control. Canines and humans do not have an inverted yolk sac. Thus, it has been hypothesized that teratogenic effects of HBOC-201 do not apply to humans, however, more studies are needed. At least one US expanded access study allows pregnant women with the potential of massive blood loss (e.g. those with placenta accreta, placenta percreta) to consent to the study while still pregnant. However, HBOC201 cannot be given until after delivery.

HBOC-201 in this case was utilized as a means to reverse severe end-organ damage due to anemia. This Jehovah's Witness patient refused blood products, citing religious beliefs. Jehovah's Witnesses in general will not receive "primary" blood components which include red blood cells, platelets and plasma. Other components, including albumin, clotting factors and HBOCs are considered "conscience items" through the church, where-in the individual can decide for themselves if they wish to receive them (5). With an estimated 1.2 million Jehovah's Witnesses in the United States alone, alternative treatment options for this patient population are imperative (5).

While transfusion of allogeneic blood products remains the standard of care for treatment of severe post-partum hemorrhage, there are certain situations where this is not available. These might include lack of resources in a rural setting, blood product shortages, and inability to cross-match blood products given patient antibodies or patient denial of blood products due to personal or religious 
beliefs. HBOC's are currently not approved for use in the United States, however they can be used on a limited compassionate use basis with FDA IND and local IRB approval, either as part of a planned expanded use study or on an emergency approval basis. Referral to a center with an expanded use protocol should be considered for a woman with the potential for massive bleeding who cannot receive RBC.

\section{References}

1. Enakpene CA, Morhason-Bello IO, Enakpene EO, Arowojolu AO, Omigbodun AO. Oral misoprostol for the prevention of primary post-partum hemorrhage during third stage of labor. J Obstet Gynaecol Res. 2007 Dec;33(6):810-7. [CrossRef] [PubMed]

2. Say L, Chou D, Gemmill A, Tunçalp Ö, Moller AB, Daniels J, et al. Global causes of maternal death: a WHO systematic analysis. Lancet Glob Health. 2014 2(6):e323-e333.[CrossRef] [PubMed]

3. Creteur J, Vincent JL. Hemoglobin solutions. Crit Care Med. 2003 Dec;31(12 Suppl):S698-707. [CrossRef] [PubMed]

4. Marinaro J, Smith J, Tawil I, Billstrand M, Crookston KP. HBOC-201 use in traumatic brain injury: case report and review of literature. Transfusion. 2009 Oct;49(10):2054-9. [CrossRef] [PubMed]

5. Epperla N, Strouse C, VanSandt AM, Foy P. Difficult to swallow: warm autoimmune hemolytic anemia in a Jehovah's Witness treated with hemoglobin concentrate complicated by achalasia. Transfusion. 2016 Jul;56(7):1801-6. [CrossRef] [PubMed]

6. Greenburg AG, Kim HW. Hemoglobin-based oxygen carriers. Crit Care. 2004;8 Suppl 2:S61-4. [CrossRef] [PubMed]

7. Fitzgerald MC, Chan JY, Ross AW, Liew SM, Butt WW, Baguley D, et al. A synthetic haemoglobin-based oxygen carrier and the reversal of cardiac hypoxia secondary to severe anaemia following trauma. Med J Aust. 2011 May;194(9):471-3. [PubMed]

8. Mongan PD, Moon-Massat PF, Rentko V, Mihok S, Dragovich A, Sharma P. Regional blood flow after serial normovolemic exchange transfusion with HBOC-201 (Hemopure $\AA$ ) in anesthetized swine. J Trauma. 2009 Jul;67(1):51-60. [CrossRef] [PubMed]

9. Serruys PW, Vranckx P, Slagboom T, Regar E, Meliga E, de Winter RJ, et al. Haemodynamic effects, safety, and tolerability of haemoglobin-based oxygen carrier-201 in patients undergoing PCI for CAD. Eurolntervention. 2008 Mar;3(5):600-9. [CrossRef] [PubMed]

10. Van Hemelrijck J, Levien LJ, Veeckman L, Pitman A, Zafirelis Z, Standl T. A safety and efficacy evaluation of hemoglobin-based oxygen carrier HBOC201 in a randomized, multicenter red blood cell controlled trial in noncardiac surgery patients. Anesth Analg. 2014 Oct;119(4):766-76. [CrossRef] [PubMed]

11. Jordan SD, Alexander E. Bovine hemoglobin: a nontraditional approach to the management of acute anemia in a Jehovah's Witness patient with 
autoimmune hemolytic anemia. J Pharm Pract. 2013 Jun;26(3):257-60. [CrossRef] [PubMed]

12. Mer M, Hodgson E, Wallis L, Jacobson B, Levien L, Snyman J, et al. Hemoglobin glutamer-250 (bovine) in South Africa: consensus usage guidelines from clinician experts who have treated patients. Transfusion. 2016 Sep. [CrossRef] [PubMed]

13. Donahue LL, Shapira I, Shander A, Kolitz J, Allen S, Greenburg G. Management of acute anemia in a Jehovah's Witness patient with acute lymphoblastic leukemia with polymerized bovine hemoglobin-based oxygen carrier: a case report and review of literature. Transfusion. 2010 Jul;50(7):1561-7. [CrossRef] [PubMed]

14. Stump DG, Holson JF, Harris C, Pearce LB, Watson RE, DeSesso JM. Developmental toxicity in rats of a hemoglobin-based oxygen carrier results from impeded function of the inverted visceral yolk sac. Reprod Toxicol. 2015 Apr;52:108-17. [CrossRef] [PubMed]

15. Holson JF, Stump DG, Pearce LB, Watson RE, DeSesso JM. Absence of developmental toxicity in a canine model after infusion of a hemoglobin-based oxygen carrier: Implications for risk assessment. Reprod Toxicol. 2015 Apr;52:101-7. [CrossRef] [PubMed] 